\title{
Por um rádio de vanguarda política e estética
}

\author{
Marcelo Kischinhevsky e Sonia Virgínia Moreira \\ (Colaboração da bolsista de Iniciação Científica Lorena Hang)
}

Um dos pesquisadores mais representativos de rádio-arte, educação e comunicação comunitária do Brasil, o professor associado Mauro Sá Rego Costa - que até 2016 integrou o corpo docente da Faculdade de Educação da Baixada Fluminense da Universidade do Estado do Rio de Janeiro (FEBF/UERJ) - advoga a aproximação entre as rádios comunitárias, as experimentaçôes artísticas e a ação política. Para Mauro, a radiodifusão comunitária vive um momento rico, graças à emergência de uma era pós-mídia, conectada pela internet, que potencializa a circulação de áudio e traz vínculos novos, como as audiências em situação de diáspora - caso dos brasileiros que vivem nos EUA mas sintonizam uma estação de Governador Valadares (MG) via web.

Autor do livro Rádio, arte e politica (EdUERJ, 2013) e colaborador do Programa de Pós-Graduação da Faculdade de Dança Angel Vianna, o professor integra a Rede Rádio-Arte, que reúne pesquisadores de rádio, som e música do Brasil e do exterior. A produção da rede pode ser ouvida em FM e via internet pela Rádio UFMG Educativa, de Belo Horizonte, todo sábado às $14 \mathrm{~h}$ e na Rádio MEC do Rio de Janeiro, às segundas-feiras, à meia-noite. Mauro concedeu esta entrevista no estúdio do AudioLab, da Faculdade de Comunicação Social da UERJ. A íntegra em áudio está disponível na página do laboratório, no endereço: http://152.92.4.92/ audiolab/?p=3822. A seguir, os principais trechos:

Marcelo - Além de atuar na Pós-Graduação em Educação, Cultura e Comunicação na Faculdade de Educação da UERJ em Duque de Caxias, você historicamente desenvolve atividade de extensão em que concilia as experimentações e a comunicação comunitária. Pode falar um pouco mais sobre a Rádio Kaxinawá?

Mauro - Isso foi, na verdade, o começo do meu trabalho com o rádio. Eu trabalhei com todas as áreas da Comunicação. Fui jornalista de papel, no Jornal do Brasil, fiz televisão e nunca tinha feito rádio. Quando começou a história de rádio comunitária, a UERJ de Caxias tinha se mudado para a Vila São Luís, um bairro bem homogêneo socioeconomicamente, bem interessante. Eu conhecia a presidente da associação de moradores, a dona Paula, uma figura, que não é cabo eleitoral, e conversando pensamos: "Vamos fazer uma rádio 
comunitária?”. A rádio comunitária pertence à principal associação demoradores de lá - são cinco entidades locais que precisam se reunir para formar uma rádio comunitária, segundo a lei. Isso foi em 1999/2000. Fizeram reunióes na associação e criamos a rádio. A UERJ ofereceu um espaço dentro da Faculdade de Educação da Baixada Fluminense. Na verdade, criamos um laboratório de rádio para a Faculdade financiado pela FAPERJ [Fundação Carlos Chagas Filho de Amparo à Pesquisa do Estado do Rio de Janeiro]. Havia o equipamento para fazer a rádio, uma rádio excepcional: comunitária e, ao mesmo tempo, universitária. Ela está dentro da Universidade, tem a programação da comunidade e a programaçáo feita por alunos e professores da Faculdade. Criei, inclusive, duas disciplinas de rádio - acho que é o único curso de educação do Brasil que tem rádio como disciplinas eletivas, Rádio I e Rádio II, para a garotada fazer rádio.

\section{Marcelo - Recuperando o papel educativo do rádio, ao longo do século XX, esse papel importantíssimo...}

Mauro - Verdade! Depois do rádio, eles começaram a fazer televisão. Tem uma área de televisão e internet dentro da Faculdade. Trabalhamos uma formação em educação atual. $\mathrm{O}$ aluno não é professor para quadro-negro: sabe usar rádio, televisão e internet. Sabe fazer blogs, websites.

\section{Marcelo - A chamada educação para as mídias.}

Mauro - Educação de verdade!

\section{Sonia - E a rádio continua?}

Mauro - Continua. No momento está fora do ar porque pifou o transmissor e não há dinheiro para chamar o seu Jorge, que constrói transmissores de 25 watts para as rádios comunitárias das favelas, comunidades do Rio de Janeiro. Ele é da Penha e foi quem chamamos para construir o nosso transmissor e instalar a antena. Ele construiu e instalou e sempre que há algum problema, chamamos o seu Jorge para consertar: dá uma ventania, muda a direção da antena, é preciso dar um jeito e isso é contínuo. Então está com esse problema agora e, como a UERJ está sem dinheiro na crise em que estamos, há dois meses a rádio está fora do ar.

\section{Sonia - As disciplinas continuam?}

Mauro - As disciplinas continuam e continua inclusive o grupo de estudos de Deleuze e Guattari, que se reúne toda segunda-feira. É o único grupo de estudos de Filosofia do rádio no Brasil, feito numa rádio comunitária, dentro da UERJ. Eu continuo a trabalhar com o grupo, que também tem um blog que criei: gravo todas as reuniôes do grupo de estudo, está tudo lá. Esse blog é acompanhado no Brasil inteiro - em Mato Grosso, em Goiás... Gente que estuda Deleuze e Guattari, estudantes da Faculdade de Comunicação, da Faculdade de Educação da Baixada Fluminense. Isso não parou, apesar de [a rádio] estar fora do ar. Continuamos gravando os programas e colocando no blog. 
Marcelo - Hoje temos no Brasil mais de 4.700 rádios comunitárias legalizadas em operação. A diversidade de programações entre elas é muito grande, mas você vê espaço para inovações estéticas e novos formatos? Você vê o espaço da radiodifusão comunitária como um espaço de inovação?

Mauro - Olha, é meio raro. As rádios comunitárias acabam fazendo muito a imitação do rádio comercial. Não criam um estilo, uma linguagem própria, na maioria. Em algumas, por exemplo no Chapéu Mangueira, na Babilônia, morros do Leme na Zona do Sul do Rio, quem dirige a rádio é um DJ de hip hop, ligado a coisas mais atuais, faz um trabalho bacana com hip hop e com a área de música contemporânea popular. Há um pessoal da Rádio Bicuda, na Penha, que foi fechada várias vezes e só conseguiu a concessão em 2007. Antes da legislação [a lei que regulamenta a radiodifusão comunitária é de 1998], já havia uma boa quantidade de rádios no ar independente de qualquer regulamentação.

\section{Marcelo - Você acredita que a profecia de uma era pós-mídia, do ideólogo das rádios livres francesas nos anos 1980, Felix Guattari, se realiza com a internet?}

Mauro - Sim, claro, cada vez mais. É uma prática política que começou exatamente nas rádios livres da Itália nos anos 70 e na França nos anos 80 . O primeiro movimento para criar rádios livres, movimento político - a rádio Alice de Turim, a rádio Tomate, de que o Guattari participou, uma rádio ecologista em Paris - teve um reflexo no Brasil em 1985, logo que acabou a ditadura, com a rádio Xilik da USP, a rádio Se Liga, Suplicy, uma porção de rádios em São Paulo, nas universidades, fazendo um trabalho de discussão política. Elas eram, inclusive, explicitamente, ligadas às rádios italianas e francesas com essa prática política diferente do que a mídia oficia e comercial faz. Então o movimento que começou com essas rádios. Quem fala muito bem sobre isso é o Franco Berardi, um dos criadores da rádio Alice, hoje comentarista sobre política na internet, a mídia política na internet, que são os blogs, as páginas no Facebook. A internet abriu espaço para uma nova forma de comunicação: todo mundo é e pode ser produtor de conteúdo. A proposta do Guattari - embora no fim de sua vida ele achasse que estava sendo otimista demais, porque estava vendo antes de nós como o neoliberalismo estava tomando conta de tudo e a coisa ia feder e chegou a comentar no último capítulo de Caosmose, publicado em francês e que não está disponível em edição brasileira - explicita muito essa questão da força política da era pós-mídia que se faz por vários meios. Inclusive, não existia a internet de hoje, era a de 1994. Mas já havia muitas redes funcionando com linguagens diferentes. $\mathrm{O}$ grande papa dessa história foi o Tim Berners-Lee, que criou a world wide web, a www. Ele não ganhou um tostão e permitiu que todas as redes que já existiam no mundo todo - e eram muitas redes, algumas com áreas de abrangência bastante grande - se comunicassem. A www é um intertradutor de todas as redes ligadas. Já tínhamos a Bitnet, a rede das universidades, que usei quando estava fazendo o doutorado, 
entrando em contato com gente que estava pesquisando a mesma coisa. Tinha um negócio de 500 páginas que se imprimia com o endereço de todas as áreas de pesquisa e todas as pesquisas feitas no mundo em todas as universidades.

Sonia - Mauro, você está fazendo essas observações e penso que se considerarmos esse cenário hoje vivemos uma coisa completamente diferente. Você está falando das experiências numa rede de emissoras universitárias. Se considerarmos, hoje, a concentração de mídia que é cada vez maior e os grandes intermediários digitais como Google e Facebook, que espaço que você vê para a radiodifusão de caráter não-comercial?

Mauro - Eu acho que o espaço existe. Tive uma experiência curiosa há pouco tempo com o Cacau Arcoverde, que faz uma rádio chamada Catimbau em Arcoverde, uma cidadezinha de 10.000 habitantes a $200 \mathrm{~km}$ de Recife. A webrádio fica 24 horas no ar. Eu bati um papo no Skype com ele, uma figura fantástica e disse: "Você tem uma equipe aí pra colocar a rádio 24 horas por dia?”. E ele respondeu: "Não, faço sozinho". Ele tem aquele sisteminha de automação que programa tudo automaticamente. Ele entrou em contato comigo porque ouviu a Rede Rádio-Arte na Rádio MEC e está colocando rádio-arte no sertão de Pernambuco. Então, são coisas capilares, pontuais mas há um espaço para inventar um outro rádio pelo mundo afora - como o pessoal que fez a rádio da Bienal de São Paulo em 2012, Sarah Washington e Knut Aufermann, uma inglesa e um alemão. Foram chamados pela bienal de São Paulo em 2012, mantiveram uma rádio todo o período da Bienal no ar. E está no ar até hoje: no mobile-radio.net se ouve os programas feitos naquela Bienal de 2012 porque há um arquivo muito bom de podcasts. Enfim, esse pessoal atua dando apoio a rádios diferentes, transversais, pelo mundo afora - fizeram a rádio Zero nas bienais de rádio em Lisboa e encontros de rádio em vários lugares, como Alemanha, Suécia, Eslovênia, criando estações de rádio comunitárias. Há várias estaçôes comunitárias na Inglaterra, por exemplo, fazendo rádio-arte. Não se trata de webrádio: são estaçôes comunitárias de cidades próximas de Londres - como a Radio Art, a Ressonance. Quem está interessado nessa área encontra.

\section{Sonia - Para você, mesmo a legislação das rádios comunitárias nos anos 1990 não conseguiu esvaziar esse caráter inventivo? Essa utopia permanece hoje?}

Mauro - Permanece. Inclusive, a ideia de que ninguém dá bola para webrádio, tipo "quem ouve?" O Cacau Arcoverde, da rádio Catimbau, tem uma audiência enorme porque fez um bom trabalho de divulgação, propaganda, de uma rádio do meio do sertáo de Pernambuco. Uma das rádios mais ouvidas em Boston [capital do estado de Massachusetts nos EUA] é de Governador Valadares, em Minas Gerais, ouvida pela comunidade brasileira [vivem oficialmente na cidade mais de 60 mil brasileiros, mas há estimativas de que o número passe de $200 \mathrm{mil}^{\mathrm{l}}$. A internet facilitou [ouvir] fora dos aparelhos de rádio, nos blogs, nos sites etc., mas incluindo o 
rádio na possibilidade dessa era pós-mídia que está viva. Estou inclusive participando de encontros de grupos no momento por causa da situação política que estamos vivendo no Brasil. Há um no Maranhão, tentei formar um aqui no Rio, estou ligado a outro grupo que está se formando... Como nos juntamos em massa? Minha proposta era criar uma plataforma para o nosso candidato para a eleição de 2018, uma plataforma nacional com 60 milhóes de pessoas, de preferência. Como vamos eleger um presidente novo com o Congresso que está aí e com esse clima político totalmente podre, corroído?

\section{Sonia - Você não acha que as rádios comunitárias ajudam por- que elas têm uma identificação local muito grande? E conse- guindo a rede na verdade maximiza isso?}

Mauro - Na verdade, há casos. A maior parte das rádios comunitárias não faz nada que preste, mas existem rádios comunitárias pelo Brasil como as que falei, do morro do Chapéu Mangueira e Babilônia, a rádio do [morro do] Cantagalo, que fazia uma programação para atingir os moradores da Lagoa. Eles estão no meio da favela, no morro do Cantagalo, mas não pensam: "Vamos fazer uma rádio só pra gente. Vamos influir no entorno, que é a área mais rica da população da Zona Sul”. Tem também o pessoal da rádio Bicuda... E outra coisa: são 4.700 rádios oficialmente no ar, mas existem 40.000 rádios livres. Além das 4.700 outras 36.000 entram no ar, saem do ar, a polícia pega, abrem de novo pelo Brasil afora fazendo todo o tipo de coisa - desde aquela comercialzinha para ganhar um dinheiro fazendo propaganda do supermercado local (são muitas rádios comerciantes). A metade dessas 36.000 é das igrejas evangélicas que estão fora da lei "em nome de Jesus" e fazendo esse trabalho. Há, inclusive, rádios comunitárias controladas pela igreja local, que mesmo assim fazem um bom trabalho, têm respeito e atenção pelas questóes locais apesar da direção erradamente. As igrejas tomam conta até das rádios comunitárias oficiais, além de terem todas as outras não-oficiais que se espalham pelo Brasil afora, dentro de aldeias indígenas, por todo o lado... É um perigo.

Sonia - Uma coisa interessante: a rádio-arte fala de uma linguagem universal. A rádio-arte nesse exemplo de Pernambuco que você citou é típico, não é? Há interesse por essa linguagem universal.

Mauro - Ainda bem, né? Existe pelo mundo afora. Eu torço para aparecer uma fábrica que faça rádio de carro, porque eu não sei usar Bluetooth para poder colocar o telefone 'tocando' no rádio do carro, não aprendi ainda. Mas tinha que ter um rádio no carro que 'pegasse' internet. Aí teria acesso a 500 rádios pelo mundo afora que fazem coisas que prestam e que a gente não ouve. 
Marcelo - Esse rádio via internet no carro existe. 0 problema é que as montadoras têm acordos com os grandes consórcios de rádio digital nos Estados Unidos e na Europa. Então isso acaba não chegando ao consumidor final porque não interessa aos grandes players de mercado essa possiblidade de escolhas infinitas.

Mauro - Exatamente!

Marcelo - Historicamente, temos acordos entre as associações de montadoras de automóveis e a indústria de radiodifusão para que o cardápio de opções fique dentro ou do rádio hertziano ou do rádio digital, que tem hoje na Europa e nos Estados Unidos, ou o rádio via satélite também, que tem nos Estados Unidos por assinatura.

Mauro - Só para concluir: essa história de rádio-arte começa com o próprio rádio. As primeiras rádios na Alemanha nos anos 1920 tinham artistas fazendo rádio. Walter Benjamim fazia programas para crianças no rádio, Brecht fez rádio, todo mundo que tinha alguma coisa na cabeça na Alemanha, nos anos 1920, antes do nazismo. Quando o nazismo subiu, acabou com essa história. Mas tinha uma rádio de vanguarda, o hörspiel, que é o radiodrama. Depois da guerra veio o neuhörspiel [o novo radiodrama]. A Alemanha é vanguarda na rádio-arte desde os anos 1920 e retomou depois que acabou a guerra. Na verdade, só retomou em 1961, muito curiosa essa história. $\mathrm{O}$ poder do controle governamental era nazista e, quando acabou o nazismo, continuaram os [controles dos] governos na Alemanha, na França, na Itália e no Japão. Por causa da guerra, não tinha rádio comercial. Na França e na Itália, o movimento das rádios livres começa para criar uma rádio não-estatal, porque [até então] só tinha rádio estatal. No Japão também. Aliás, o cara que fez no Japão é um gênio, Tetsuo Kogawa. Ele fez um transmissor de rádio usando um aparelhozinho de controle remoto de carrinho. Ele juntou um controle remoto de carrinho com um microfone e montou um transmissor de rádio com 0,5 watt, que pegava até o fim do corredor. Ele fazia com os estudantes da Universidade de Tóquio. Depois criaram uma rádio no centro de Tóquio, essa coisa transbordou e, de repente, em Tóquio havia 2.500, 5.000 rádios. A Mitsubishi e a Sony passaram a construir transmissores de rádio de 0,5 watt e faziam rede dos transmissores - coisa proibida na legislaçáo brasileira de rádio comunitária, não se pode fazer rede. O Kogawa fez isso porque foi para a Itália e para a França, acompanhou o movimento das rádios livres. Então tem uma história, essa história da rádio criadora, politicamente avançada, mas também artisticamente. A rádio Alice, por exemplo, foi uma rádio política ligada aos movimentos de vanguarda na Itália na época, mas tocava John Cage, a programação sonora também era de primeiríssima. Há uma proximidade do rádio com a arte, do rádio como ação política de vanguarda. Sempre andaram juntos e isso é uma coisa que precisamos retomar. Vamos retomando aos poucos!

\section{Notas}

1. Segundo estimativa do Ministério das Relaçôes Exteriores, na regiâo atendida pelo Consulado de Boston, que abrange os estados de Massachusetts, Maine, New Hampshire e Vermont, viviam 355 mil brasileiros em 2011. Disponível em: http:// www.brasileirosnomundo.itamaraty.gov.br/. Última consulta: 17/6/2017. 